\title{
Learning by Doing: Action Research to Evaluate Provisions for Gifted and Talented Students
}

\author{
Associate Professor Tracy Riley \\ Massey University \\ Professor Roger Moltzen \\ University of Waikato
}

\begin{abstract}
Between 2006 and 2008 the Ministry of Education funded the evaluation of three Talent Development Initiatives for gifted and talented students. The methodology employed was one of participatory action research, a process of evaluation that enables learning by doing, as researchers and practitioners work alongside one another. Through the process of evaluating the three programmes, the researchers were also able to reflect on how and what formative feedback effects the development, implementation, maintenance, and evaluation of provisions for gifted and talented students. Based upon notes from team meetings, ongoing communications, and focus group discussions, the researchers concluded that an action research approach, despite some tensions, is useful and instrumental in the ongoing development of provisions for gifted and talented students.
\end{abstract}

\section{Research paper}

Keywords: Gifted and talented, participatory action research, talent development initiatives

\section{INTRODUCTION}

The Talent Development Initiatives were launched by the previous government as one of a series of work programmes to enhance educational opportunities for gifted and talented students, their parents, and educators. Between 2003 and 2008, two contestable funding rounds enabled over thirty-five providers to develop a range of initiatives. These included a wide diversity of innovative programmes, using different organisational structures, aimed at a variety of target groups and needs, provided by both schools and private providers. The original purposes in the contestable funding, as outlined by the (Ministry of Education, 2002), were to:

- Develop innovative approaches to gifted and talented education that would result in improved outcomes for students.

- Research the impact of innovative approaches on teaching and learning.

- Disseminate knowledge, understanding, and models of effective practice.
During the second round of funding, two types of initiatives were funded (Enhance and Ignite programmes) and a team of researchers was contracted to evaluate some of the initiatives. The Enhance programmes were selected for continued funding to further develop and build upon their innovations from the first round, and the Ignite programmes were new programmes with a targeted focus on specific groups of students (e.g., Māori and Pasifika, rural, low-income). Between 2006 and 2008 the researchers evaluated two Enhance programmes of professional development and support for teachers using a case study approach, and three Ignite programmes designed for gifted and talented students using an action research approach.

The evaluation of these five programmes has been reported by Riley and Moltzen (2010), and this article focuses on only one slice of the full report: action research to evaluate provisions for gifted and talented students. At the outset, it is important to clarify that we do not believe action research and evaluation research to be dichotomous or in conflict with each other. We also adopt the position of Potter (2006): there is no one correct way to conduct programme evaluation. Rather, we take the stance that the evaluation of gifted programmes should utilise a responsive research approach which incorporates collaboration, opportunities for improvement and change through an iterative process, and, ultimately, leads to empowerment of participants and sustainability of programmes. "Evaluation employs an inquiry cycle that iteratively frames and examines problems of practice, chooses actions to address the problems, assesses the effects of these actions, and then reframes the original problems of practice" (Rallis \& Militello, 2009, p. 254).

This definition of evaluation fits well with action research, which, as its name implies achieves "both action and research outcomes in a single study" (Dick, 1997, no page given). We believe that an action research evaluation encourages people to look at what is happening, reflect upon how programmes are developing, and make changes as they are going along, rather than just evaluating them at the end. In other words, 
the focus of such an evaluation is on action or change, or continuous improvement. Potter (2006) would argue that the approach to evaluation we are describing is underpinned by a criticalemancipatory paradigm - one which aims for transformation through evaluation.

The article begins by describing what we know about the evaluation of gifted programmes in New Zealand, followed by an explanation of the underlying principles and practices. The advantages and disadvantages of learning by doing, as perceived by the participants and researchers, are described, with recommendations for practice.

\section{WHAT DO WE KNOW?}

In New Zealand, gifted and talented provisions are seldom formally evaluated and reported upon, resulting in "a paucity of ... research which evaluated the effectiveness of provisions ... in relation to social, cultural, emotional, creative, and intellectual outcomes" (Riley, et al., 2004, p. 3). This lack of reported evaluations leaves New Zealand's practitioners in a vulnerable position of adapting or adopting international practices without a "critical, research-driven analysis of their appropriateness" (Riley \& Moltzen, 2010, p. 5) within our own cultural and educational landscape. While there is a growing body of information about gifted and talented provisions, without empirical research evidence it is difficult for teachers to make informed decisions or reliably test the efficacy of chosen practices.

And yet, what we know, from reports of the Education Review Office (2008) and Ministry of Education (Riley et al., 2004), is that only around a quarter of schools employ evaluation methods. In 2007, the Education Review Office collected data on 315 schools, reporting that nearly half of the schools $(46 \%)$ had not developed any processes of evaluation as would be indicated by:

- systematic and ongoing processes for evaluating student outcomes;

- sharing and consultation about evaluation findings with key stakeholders;

- actions based on the recommendations of evaluations, and

- evaluations of provisions both internal and external to the school.

If these indicators were evidenced in schools or other services for gifted and talented students, chances are they would be better armed to make good decisions and to be responsive to students' needs. On the other hand, the lack of good evaluation data can result in an insufficient programme infrastructure which can potentially lead to superficial provisions (Van Tassel-Baska, 2004a). Therefore, in some ways it is not surprising, that after a three year action research-based evaluation of programmes for gifted and talented students, Riley and Moltzen (2010) concluded that each of the programmes demonstrated a dynamic approach to programme development, implementation, and evaluation. Using formative evaluations, the providers were able to collect information from key stakeholders and respond to their findings to improve their provisions. This needs-based approach requires "flexibility, adaptability, creativity, and innovation" (Riley \& Moltzen, 2010, p. 143). These same factors are important in evaluating provisions for gifted and talented students, as the next section explains.

\section{WHAT DO WE NEED TO KNOW?}

There are two interconnected elements of evaluation: the outcomes for students and the effectiveness of the programme (Taylor, 2000). Academic, social, cultural, emotional, creative, and intellectual outcomes contribute to a programme's overall effectiveness, and, similarly, the effectiveness is in one part determined by evidenced outcomes for students. The effective implementation of a programme is determined by measuring the effectiveness of management objectives, while the programme objectives determine outcomes for students (Gallagher, 1998). Thus, provisions need to be measured based on input (i.e., resources), processes (i.e., identification and differentiated programmes), and outputs (i.e., student outcomes) (Taylor, 2000). To do this, evaluation needs to be ongoing and based on formative and summative approaches.

The National Association for Gifted Children in the United States (1997) suggests different approaches to evaluation: incoming evaluations, or needs analyses; transition evaluations (when students move from one programme to another); year-end evaluations; and ongoing evaluations. Ongoing evaluations enable timeliness: a chance to measure the process of development, to test innovation, and gather formative data (Van Tassel-Baska, 2004b). This requires an eclectic mix of evaluation types, as described by Van Tassel-Baska (2004b):

- Case study approaches answer the questions of how and why by providing rich, thick descriptive data from multiple perspectives.

- Utilisation-focused approaches embed evaluation methods into programme development and implementation, enabling the data to influence programme changes. 
- Client-centred approaches focus on the needs of a provision's key stakeholders by enabling their direct involvement in shaping, contributing to, and providing feedback for the evaluation.

- Context, input, process, product approaches measure the extent to which the programme's goals have been met by considering how these four factors have been evidenced in the programme planning, documentation, and procedures.

Ideally, any evaluation of provisions for gifted and talented students would take on a mix of these approaches, weaving together all these foci by gathering data from multiple sources and analysing these both quantitatively and qualitatively. Using interviews, observations, document analysis, surveys, and outcome-based evidence enables evaluators to triangulate different data sources from different perspectives, as well as substantiate findings through recurring themes, patterns, or issues.

To do this requires a team approach, inclusive of the many stakeholders in gifted and talented programmes: administrators, teachers, parents and whanau, community members, and the students themselves (Riley \& Moltzen, 2010). Tomlinson and Callahan (1994) also recommend the inclusion of qualified evaluators - experienced, skilled, and knowledgeable 'experts'. Each of these stakeholders will have different evaluative questions, interests, and purposes (Reid, 2004), but by including many perspectives, the evaluation will generate greater support, shared understandings, and opportunities for implementing recommendations (Tomlinson \& Callahan, 1994). As Van Tassel-Baska (2004b) states, "Involvement increases relevance, understanding, and ownership of the evaluation, all of which facilitate informed and appropriate use" (p. 20) of the results.

However, evaluation is complex and not without problems. Difficulties in the evaluation of gifted and talented programmes stem from deeper issues in the field. For example, differences in definitions and identification of giftedness and talent means that any generalisations across different evaluation approaches or results should only be made with caution. Measuring multi-faceted student outcomes, including emotional, social, and cultural outcomes, is unachievable using standard measures of assessment: alternative and above-level measures need to be utilised. Given the nature of some gifted programmes and the individuality of students, it would be difficult to pinpoint 'the programme' as the sole cause for any change or growth. As Winner (1996) explained, this could only be achieved by random sampling - identifying students as gifted and talented and then implementing an intervention with one group (treatment) but not another (control). As Reid (2004) reminds us, research of this nature creates ethical dilemmas. Therefore, in the evaluation of gifted and talented programmes, it is important to take individual differences into consideration, avoid sweeping generalisations or cause-effect conclusions, and employ appropriate measures.

To summarise, evaluations of gifted and talented programmes should provide information for improvements using a collaborative process to gather data from multiple sources (Van TasselBaska, 2004c). What this enables is a dynamic interplay between programme planning and development, implementation, and evaluation which Van Tassel-Baska (2004c) describes as a cyclical process of planning, doing, studying, and acting. Taking all these considerations into account, it makes sense to use an action research approach.

\section{LEARNING BY DOING}

Participatory action research is "a systematic inquiry by collaborative, self-critical communities ... out of the need to improve educational knowledge and practices" (Watts \& Watts, 1993, p. 36). Grundy (1982) described the underlying principles of participatory action research as collaboration and participation, empowerment, knowledge, and social change. Through authentic and committed participation, communities of people open themselves up to enlightenment about the relationships between "circumstance, action, and consequence" (Wadsworth, 1997, p. 70). Through dissemination and sharing of their experiences, this enlightenment is extended to other stakeholder groups. These ideas align well with what we know about the evaluation of gifted and talented programmes, and particularly the testing of innovative approaches.

What an action research approach entails is a spiral of steps taken by teams of researchers and programme stakeholders. These steps can be applied to the evaluation of provisions as follows:

1. Develop a plan of action for evaluating outcomes and processes.

2. Act to implement the plan by undertaking the evaluation.

3. Observe the effects of the action by documenting the evaluation.

4. Reflect on the action and plan further action for the evaluation. 
By using this sort of approach, an evaluation would be both responsive and illuminative. A major benefit is that the evaluation is not just summative, but also formative, enabling "judgement of the worth of the programme while it is forming or happening. It also allows for the programme to be shaped based on an ongoing evaluation, rather than a 'too-late' evaluation" (Riley \& Moltzen, 2010, p. 12). Using this design also allows providers to build records of improvement and, if planned at the outset of programme development, to tell the story of programme evolution.

For the evaluation of the Talent Development Initiatives for gifted and talented students, an action research approach was employed over three years with teams of researchers working alongside practitioners. Each team included three academics with experience and knowledge in gifted and talented education, as well as curricular knowledge related to subjects or levels of teaching. The initiative's director(s) were also part of each team.

The teams worked together to develop processes for determining the most appropriate approaches and perspectives for answering the Ministry of Education's research purposes:

- To determine how providers design, implement, maintain, and evaluate programmes for gifted and talented students.

- To determine how providers structure relevant and engaging learning and growth opportunities for gifted and talented students, as evidenced in the achievement of programme objectives; improved outcomes for students; impact upon key stakeholders, and planning for sustainability.

- To determine how, and what, formative feedback effects the development, implementation, maintenance, and evaluation of programmes for gifted and talented students, by using an action research approach to evaluation (Riley \& Moltzen, 2010, p. 2).

Thus, each year represented a cycle of research framed by a broad question:

1. Cycle 1: What is going on?

2. Cycle 2: Is it working?

3. Cycle 3: How do we know?

In other words, during the first year of programme development, the focus was on programme design and implementation. As researchers, who were external to the conceptualisation and creation of the programmes, it was important to gain a sense of how students were being identified: what curriculum adaptations were being made; how the content, processes, and products were differentiated, and how the providers would determine programme effectiveness with their own internal processes. By the second cycle, it was time to focus upon how those decisions were working in practice: were they effective measures of identification, differentiated provisions, and so on? In the final year, while effectiveness was still of great importance, it was also timely to ask questions related to sustainability, evaluation processes in practice, personnel, and programme impacts.

Each of the three case studies was evaluated using several methods of data collection: document analysis; observation; surveys, and interviews (focus group and individual). Perspectives were sought from all stakeholders, including gifted and talented students, the programme director(s), teachers, mentors, and parents. For each case study different data methods were used with different stakeholder groups, but all participants were wellinformed of the reasons for and implementation of action research in the evaluation. All participants were also provided with a detailed information sheet and asked to provide informed consent, as per the Massey University Human Ethics Committee guidelines.

Throughout the three years of the evaluation, the research teams met regularly, communicated over email and phone, and kept research diaries. During the final research team meeting in 2009, a doctoral student was hired to conduct focus group interviews with the programme directors and the academic researchers, probing their experiences and perspectives as members of an action research-driven evaluation of gifted and talented programmes. From these sources, the researchers were able to contemplate the usefulness of action research for the evaluation of gifted and talented programmes.

\section{WHAT DID WE LEARN?}

As Van Tassel-Baska (2004c) promised, by employing an action-oriented evaluation method, the researchers and programme directors were able to plan, do, study, and act as these innovative initiatives evolved. Working alongside one another through the research cycles enabled planning, implementation, evaluation, and then the creation of a plan of action for improvement. Over the three years, this approach ensured collaboration and participation, empowerment, and change (Grundy, 1982). For new programmes, which were evolving and changing as they were being implemented, this approach proved useful; however, it was not always smooth sailing. 
Also, while it should be noted that some of the perceived advantages and disadvantages of this approach may relate to other ways of conducting evaluations, what was unique in this project was the purposeful mixing of 'expert' researchers and 'expert' practitioners (Riley \& Moltzen, 2010). Using an action-driven method which emphasised change led to fluidity and responsiveness in the evaluations. For example, although the researchers were contracted by the Ministry of Education to ask a specified set of research questions, there was scope to be responsive and flexible in the ways in which those were pursued. As the programmes were shaped and evolved, so, too, did the evaluation.

\section{Advantages of Learning by Doing}

Riley and Moltzen (2010) reported an array of advantages for stakeholders in each of the programmes and including the researchers. For example, the use of a collaborative approach gave key stakeholders, including students and parents, opportunities to have a 'voice' and to influence programme development and implementation. For the gifted and talented students, "it provided opportunities for sharing their work and ideas in a broader context" (Riley \& Moltzen, 2010, p. 145). Using multiple measures of effectiveness from different perspectives ensured validation and triangulation of emerging and final results. Some of the advantages for the programme directors involved in this project included: access to relevant expert knowledge, materials, and resources; support, encouragement, and validation of practices, including wider dissemination, and professional learning and growth. Each of these advantages is elaborated in the following sections.

The programme directors had access to relevant expert knowledge by careful matching of research team members with programmes. For example, a visual arts programme was evaluated by an academic in gifted and talented education, supported by a music educator and visual artist, both of whom had professional interests in gifted and talented students. While the lead researcher was able to provide expertise on 'the big picture', his supporting artists were able to add a touch of fine detail, depth, and experience specifically related to the programme. Similarly, a marine biology programme was supported by a generalist in gifted and talented education, a science teacher educator, and a mathematics teacher educator.

Materials, resources, and expertise offered by universities also provided an advantage for the programme directors. As members of the evaluation team, the programme directors had access to library resources, including books and journals, which they otherwise would not find in their schools or centres. In one case, the programme director chose to spend several days at the Massey University campus so that he could refine his evaluative tools. This gave him access to expertise in terms of input and resources, but also the 'space' in which to focus on his work, free of distractions normally associated with his role in the centre.

Working with the researchers allowed opportunities for support, encouragement, insights, and validation of practice. Planning and implementing specialist programmes can sometimes be a rather isolated experience; however, being part of a research team provided collegial and professional support. For example, the director of a school-based programme received limited 'in-house' support, as no formal mechanisms were in place to offer such. In this case, the academic researchers "probably assumed a more influential role than might be expected to normally occur" (Riley \& Moltzen, 2010, p. 76). The director explained "They'd basically walk in the door by the end and it was just verbal diarrhoea from me most of the time - they were just the only people I could talk to, 'cos I'm quite isolated with what I do, it was like 'blah blah blah blah'" (Focus Group Interview, 2009). Another director said, "They fitted in beautifully, they fed back data, they've been very sharing. I couldn't have asked for a better team and they've been very much mentors" (Focus Group Interview, 2009).

Assistance and support in ongoing dissemination of practice was a real benefit for the directors. The programme directors presented nationally and internationally at conferences, sometimes in collaboration with the academic team members. Collaborative writing projects have also eventuated. As one of the directors, who had presented a workshop with one of the researchers, shared, "I think that was a huge boost for me, a learning curve for me" (Focus Group Interview, 2009). Riley et al., (2004) concluded that the dissemination of New Zealand-based research in gifted and talented education is found lacking, and furthermore, when it is disseminated, it doesn't always reach practitioners. Each of these programmes has reached a range of local, national, and international audiences through presentations and publications. This has also served to enhance their own processional learning and support (Riley \& Moltzen, 2010).

Having an external perspective to programme development, implementation, and evaluation was also seen as valuable. As was stated earlier, programme coordinators can sometimes experience feelings of isolation, and as a 
programme develops, this can feel a bit like navel gazing! The academic researchers did not have the same sense of ownership of the programmes, and this afforded opportunities to provide different practical, theoretical, and researchbased ideas. The researchers could also ask the 'tough questions', enabling critical analysis of the programmes as they evolved. In the focus group discussion (2009), one of the directors explained it like this:

And it's been another set of eyes ... because once you get really close to something you can often be a little bit blind and blinkered to things and it's been really important to have someone else see it from another perspective.

As a result of all these advantages, each director also had opportunities for, and showed evidence of, professional growth. As one of the directors shared in the focus group interview (2009),

As part of the process of doing ... your own professional development is happening - whether you want it to or not, in a sense. And so it's like whoever you're working with, you're moving them along, and ... you are having to move along yourself.

This seems unique to the methodology, as the hands-on involvement in the evaluation ensured the directors were not 'outside' the process, results, or conclusions, but firmly cemented within the action research.

Similarly, there were advantages for the academic researchers. Firstly, there was the opportunity to be engaged in practice which created "practiceinformed research, an often overlooked link between theory and practice whereby research usually drives practice" (Riley \& Moltzen, 2010, p. 145). Being external to the programme's conceptualisation, and to a lesser degree its implementation, meant that any research or theory-driven ideas really had to be contemplated in relation to practice, and considerate of programme development. As one of the research team members explained, "It made me think, if I'm evaluating, at the same time 'How can I feedforward for the people I'm evaluating, working alongside them, that helps them move forward and then spurs another bit of growth?'" (Focus Group Interview, 2009). This responsiveness took at least one researcher a while to grow accustom to: she referred to this as "delayed resolution as a researcher" (Focus Group Interview, 2009).

Also, involvement in practice-driven research influenced tertiary teaching by developing understandings of giftedness, provisions, and evaluation, and providing examples of practice. One researcher explained it like this:

It was kind of a reinforcement of characteristics if you like, of gifted and talented students, the importance of working with like-minded peers, and I think the key for me, the biggest growth, was my understanding of how mentors could be used (Focus Group Interview, 2009).

Another researcher felt her involvement in a secondary programme added to her "credibility" as a lecturer with a background in primary education. Research skills and abilities were also developed and there was great value placed on working as part of a team with a balance of experiences, skills, and backgrounds.

There were clearly positive spin-offs for all those involved in the evaluations, and the researchers became a natural part of the Talent Development Initiatives. But this was not without tensions and issues, especially for the academic researchers, which the next section describes.

\section{Tensions for Researchers}

From the outset of these evaluations, it was important that there be an established level of trust between the researchers and the programme stakeholders. In initial discussions with the programme providers, while on the one hand they were willing to cooperate, on the other hand it was not without some scepticism, wariness, and possibly even fear of criticism. Action research requires the development of collaborative, trusting and respectful relationships, but this was heightened by the fact that both the Talent Development Initiatives and the evaluation approach were innovative and still under development. So, in a sense, not only were the programmes evolving, so too was the research.

Not surprisingly then, finding a balance between the research process and final product was at times difficult for the researchers. How important was it to help develop, shape, and even influence the programme while at the same time pursuing the research questions? Similarly, it was at times difficult to maintain and demonstrate respect and understanding for the programme's circumstances and needs, while operating within a defined set of research parameters. Riley and Moltzen (2010) describe this as a tension between 'bottom-up' or 'top-down' approaches to research. For example, one of the research team members described her dilemma when asked to conduct parent meetings, and being advised by one of the research directors not to do so: "I would have fallen into the trap 
of being more involved in the process of the programme rather than knowing quite where to draw the line" (Focus Group Interview, 2009).

It was also difficult defining the roles of the researchers and the participants. These roles shifted throughout the research, ranging from novice to expert, researcher to practitioner, and insider to outsider. The researchers were academics with expertise in theory and research, while the programme directors were expert practitioners. But even within the research teams, there was a complexity of expertise in both research methods and contexts. Over the three years of the research, however, all these roles shifted. The programme directors were defined initially by their teaching practice, but were expected to become active researchers. Similarly, the researchers were marked by their academic expertise and expected to become involved in practice.

As the action research progressed, the lines between researchers and practitioners became fuzzy and expertise more balanced. For example, as questions and problems arose, solution-finding became more collaborative, particularly as each cycle of the research progressed. A researcher described the changing roles in this way: "And it's also that they feed back and you work collaboratively with them and then something new evolves from it and the pathway is explicit and obvious" (Focus Group Interview, 2009). There was greater sharing of the ownership of both the research and programmes' problems. But this also caused dilemmas: "Yeah there were problems with boundaries, with boundaries around the programme" (Researcher, Focus Group Interview, 2009).

As has been described, both the researchers and programme directors demonstrated professional growth, and this aided in the fluidity of roles. Across and within the teams the research roles and programme roles became more transferable and interchangeable. Building on individuals' strengths enabled a collaborative sharing of tasks as both problem-finders and problem-solvers. While this sounds positive, and to a large degree it was, for the researchers it created a tension between the roles of collaborator and external evaluator. The researchers were acting in two roles, insiders and outsiders, and there was some danger in objectivity being lost as relationships developed. As one of the research team members explained:

I found a real tension for me between being an evaluator and what I consider my role as an evaluator of the project, relative to what the project goals were, and, so I was really on the outside looking in, but I couldn't help but get on the inside and be a mentor so there was a sort of real tension between "Well, how much am I supposed to be taking on a role of being part of the team?" to feed-back, feed-forward (Focus Group Interview, 2009).

It was also difficult at times to be critical of the programmes, especially when sometimes these were derived from theory and research developed by members of the research teams. It was also difficult to know when to be hands-on or handsoff. Another team member described the conflict like this: "that grey area ... where we're outside the organic model so to speak versus how much we put inside and lead" (Focus Group Interview, 2009). There were role conflicts that evolved: researcher versus expert, researcher versus monitor, and supporter versus advocate.

\section{WHERE TO FROM HERE?}

Programmes for gifted and talented students should be evaluated both formatively and summatively, using internal and external processes, and inclusive of a variety of stakeholder voices heard through multiple measures. One important element that is sometimes overlooked is the importance of establishing the framework and design of an evaluation at the outset of programme development. Using an action research approach provides the flexibility and fluidity needed for parallel evolution of the programme and the evaluation.

More research is needed to test the viability and strength of action research approaches to programme evaluation in gifted and talented education, but from this preliminary work, a set of practical recommendations for evaluation arise. When designing and implementing programme evaluations for gifted and talented education, educators should consider:

1. Using a team approach which is inclusive of stakeholders from within the school community, but also professionals external to the school who may have expertise.

2. Carefully matching the evaluation purposes with the methods of data collection.

3. Developing trust and clarifying roles of all those involved in the evaluation process.

4. Using the results of evaluation for programme improvement; this requires gathering practical information by asking practice-driven questions. 


\section{REFERENCES}

Dick, B. (1997). Qualitative evaluation for program improvement. Available at http://www.scu.edu.au/ schools/gcm/ar/arp/qualeval.html

Education Review Office. (2008). Schools' provisions for gifted and talented students. Wellington: Evaluation Review Reports.

Gallagher, J. (1998). Accountability for gifted students. Phi Delta Kappan, 79(10), 739-743.

Grundy, S. (1982). Three modes of action research. In S. Kemmis \& R. McTaggart, The Action Research Reader. Geelong: Deakin University Press.

Ministry of Education. (2002). Initiatives in gifted and talented education. Wellington: Ministry of Education.

National Association for Gifted Children. (1997). Using tests to identify gifted students. Retrieved April 29, 2010 from http://www.nagc.org/index. aspx?id=404

Potter, C. (2006). Program evaluation. In M. Terre Blanche, K. Durrheim \& D. Painter (Eds.), Research in practice: Applied methods for the social sciences (2nd ed.) (pp. 410-428). Cape Town: UCT Press.

Rallis, S. F., \& Militello, M. (2009). Inquiry-minded district leaders. In K. E. Ryan \& J. B. Cousins (Eds.), The SAGE international handbook of educational research (pp. 253-272). Thousand Oaks, CA: SAGE Publications.

Reid, N. (2004). Evaluation of programmes. In D. McAlpine \& R. Moltzen, Gifted and talented: New Zealand perspectives (pp. 377-390). Palmerston North: Kanuka Grove Press.

Riley, T., Bevan-Brown, J., Bicknell, B., Carroll-Lind, J., \& Kearney, A. (2004). The extent, nature, and effectiveness of identification and provisions for New Zealand gifted and talented students. Final report. Wellington: Ministry of Education.

Riley, T., \& Moltzen, R. (2010). Enhancing and igniting Talent Development Initiatives: Research to determine effectiveness. Wellington: Ministry of Education.

Taylor, S. (2000). Assessment and evaluation. Retrieved April 29, 2010, from tki: http://www.tki. org.nz/r/gifted/reading/assessment/assess_eval_e. php

Tomlinson, C., \& Callahan, C. (1994). Planning effective evaluations for programs for the gifted. Roeper Review, 17(1), 46-52.

Van Tassel-Baska, J. (2004a). Metaevaluation findings: A call for gifted program quality. In J. VanTasselBaska \& A. Feng, Designing and utilising evaluation for gifted program improvement (pp. 227-256). Waco: Prufrock Press.
Van Tassel-Baska, J. (2004b). Introduction to the William and Mary Eclectic Model of Gifted Program Evaluation. In J. van Tassel-Baska \& A. Feng, Designing and utilising evaluation for gifted program improvement (pp. 1-22). Waco: Prufrock Press.

Van Tassel-Baska, J. (2004c). The processes in gifted program evaluation. In J. Van Tassel-Baska \& A. Feng, Designing and utilising evaluation for gifted program improvement (pp. 1-22). Waco: Prufrock Press.

Wadsworth, D. (1997). Everyday evaluation on the run. Australia: Allen \& Unwin.

Watts, M., \& Watts, D. (1993). Teacher research, action research: The logo action research collaborative. Educational Action Research, 1(1), 36-53.

Winner, E. (1996). The miseducation of our gifted children. Education Week, 16(7), 44.

\section{Acknowledgements:}

This research was supported with funding from the Ministry of Education, as was each of the programmes evaluated. 


\section{AUTHORS' PROFILES}

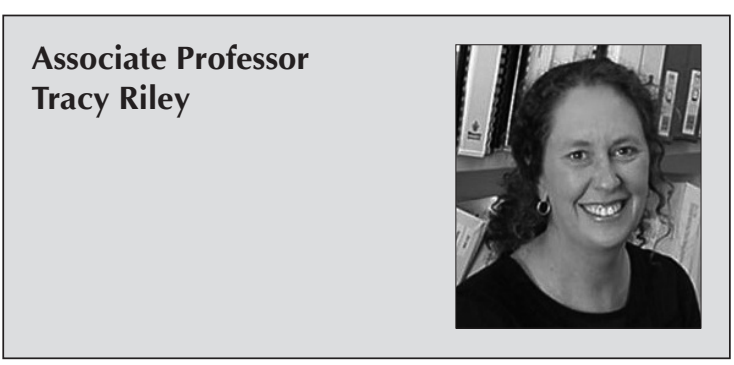

Associate Professor Tracy Riley specialises in gifted and talented education at Massey University College of Education. She teaches undergraduate and postgraduate papers in the field, as well as supervision of postgraduate research. Tracy is the coeditor of APEX: The NZ Journal of Gifted Education. An active advocate for gifted and talented students, Tracy has served on numerous Ministry of Education advisory groups and co-authored the Ministry handbook, Gifted and Talented Students: Meeting Their Needs in New Zealand Schools. In 2007, Tracy was awarded the Vice-Chancellor's Award for Sustained Excellence in Teaching and was a recipient of a national Tertiary Teaching Excellence Award. Tracy is a member of the Executive Committee of the Ako Aoteoroa Academy of Tertiary Teaching Excellent, Chairperson of the Board of giftEDnz, The Professional Association for Gifted Education, and a Trustee for the Gifted Children's Advancement Charitable Trust.

EMAIL

T.L.Riley@massey.ac.nz

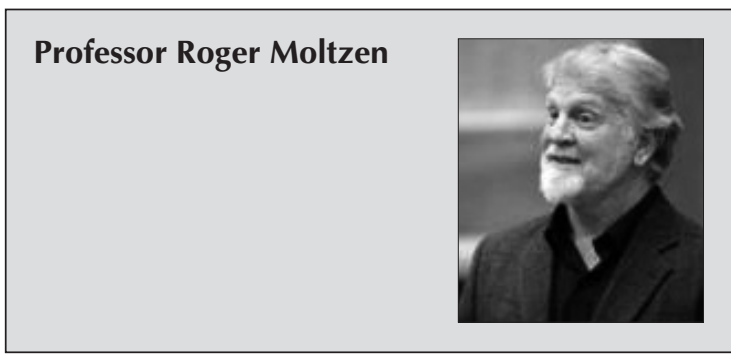

Professor Roger Moltzen teaches in courses on human development, individual differences and the education of gifted children, and is the Director of Graduate Special Education Programmes at Waikato University. His research interests are the psychology and education of gifted individuals. Roger is the Deputy Dean of the School of Education. $\mathrm{He}$ is the co-editor of APEX: The NZ Journal of Gifted Education and patron of the New Zealand Association for Gifted Children. Roger has served on numerous Ministry of Education advisory groups and co-authored the Ministry handbook, Gifted and Talented Students: Meeting Their Needs in New Zealand Schools. In 2006, he was awarded the Prime Minister's Supreme Award for Tertiary Teaching Excellence.

EMAIL

rim@waikato.ac.nz 